\title{
THE INFLUENCE OF OPERATING CONDITION ON ACOUSTIC EMISSION (AE) GENERATION DURING MESHING OF HELICAL AND SPUR GEAR
}

\author{
R.I. Raja Hamzah*, D. Mba \\ School of Engineering, Cranfield University, Cranfield, Beds. MK43 0AL, UK. \\ *E-mail: r.i.raja-hamzah.2003@cranfield.ac.uk \\ * Tel.: +44 1234 751464; fax: +44 1234751566
}

\begin{abstract}
The application of high frequency Acoustic Emission (AE) technology to condition monitoring of gears is still in its infancy. Understanding the influence of gear operating parameters on the generation of acoustic emission is essential in applying the $\mathrm{AE}$ technology to gear condition monitoring. This paper presents experimental findings on the influence of speed and load in generating AE for operating helical and spur gears. The experimental findings suggest that any percentage reduction in specific film thickness $(\lambda)$, a direct consequence of a change in load condition, results in a nine- and four-fold percentage change in AE r.m.s for the spur and helical gear sets respectively. A numerical model representing changes in AE r.m.s with variation in load and speed under near isothermal conditions for spur and helical gears was also established. In conclusion, it is postulated that the AE technology could offer a means of measuring insitu the effectiveness of a lubricant for operational spur and helical gears thereby establishing if the correct lubricating conditions are present to ensure optimal life usage.
\end{abstract}

Keywords: Acoustic Emission, Condition Monitoring, Helical Gear, Spur Gear.

\section{Introduction}


Acoustic Emissions (AE) is defined as the range of phenomena that results in structureborne propagating waves being generated by the rapid release of energy from localised sources within and/or, on the surface of a material $[1,2]$. Typical frequency content of $\mathrm{AE}$ is between $100 \mathrm{kHz}$ to $1 \mathrm{MHz}$. The application of $\mathrm{AE}$ on structural monitoring has been well established. The introduction of high frequency Acoustic Emission (AE) technology in the area of machine condition monitoring has been developing for over forty years [3]. The application of AE technology to monitoring a range of rotating machines has been detailed in recent review [3] and its growth has principally focused on applications for bearings, mechanical seals and reciprocating engines. Sources of AE in rotating machines include impacting and asperity contact.

The high sensitivity of AE in detecting the loss of mechanical integrity as compared to the well established vibration monitoring technique has become its principle advantage for machine health monitoring. However, the attenuation experienced by AE over distances and across interfaces is the main drawback of this technology.

The application of AE for gearbox diagnosis and prognosis is still in its infancy. This program of research attempts to understand the influence of operating parameters on the generation of $\mathrm{AE}$ for both helical and spur gears. It should be noted that spur and helical gears experience a combination of sliding and rolling on either side of the pitch point and pure rolling at pitch point. However, due to the geometry of the helical gears, the pitch point during gear mesh is not passed at the same time along the width of the gear like during spur gear mesh, i.e., pitch point contact for the helical gear mesh is progressive. Several researchers [4-6] have applied AE under sliding and rolling conditions and noted that asperity contact contributed to the generation of AE. 
The most vital element for maintaining the mechanical integrity of gears is its lubricant. The operating life of the gears is very much influenced by the specific film thickness $(\lambda)$, which is the ratio of the oil film thickness over the composite gear surface roughness. In practice, a ratio in excess of 2 is usually recommended for gears [7, 8]. Whilst recommendations of specific film thickness $(\lambda)$ values are publicly available the actual specific film thickness $(\lambda)$ value is difficult to ascertain during operation. Studies in elastohydrodynamic lubrication (EHL) have shown that the thickness of the oil film is mostly influenced by the temperature, surface roughness, load and speed of the meshing gears [7-9]. The possible sources of AE during spur gear mesh have been detailed [1012] with the principal source attributed to asperity interaction between the two gear surfaces in relative motion. As the specific film thickness $(\lambda)$ changes with the temperature, surface roughness, load and speed of the gears, the level of asperity contact during gear mesh will also vary.

This paper presents an experimental study that correlates AE activity to different load and speed conditions during the operation of a set of helical and spur gears. Furthermore, distinct differences in the meshing mechanisms of spur and helical gears are shown to have differing AE characteristics. This is the first known investigation at correlating $\mathrm{AE}$ and the operating condition of helical gears and forms the foundation for a significant advancement in applying the AE technology to monitoring spur and helical gears.

\section{Experimental Setup and Data Acquisition System}

The test-rig employed for this investigation was a standard back-to-back oil bath lubricated gearbox, see figure 1 . The test rig was designed to be able to accommodate 
both spur and helical gears. The test gears were made of 045M15 steel without any heat treatment. Table 1 summarizes all the test gears specifications.

Table 1 Test gears specifications

\begin{tabular}{lcc}
\hline & Spur & Helical \\
\hline Number of teeth, pinion: gear & $49: 65$ & $51: 70$ \\
Base diameter, pinion: gear $(\mathrm{mm})$ & $138.13: 183.24$ & $150.06: 205.97$ \\
Pitch diameter, pinion: gear $(\mathrm{mm})$ & $147.00: 195.00$ & $160.65: 220.50$ \\
Tip diameter, pinion: gear $(\mathrm{mm})$ & $153.00: 201.00$ & $166.65: 226.50$ \\
Contact Ratio & 1.33 & 1.37 \\
Module $(\mathrm{mm})$ & 3.00 & 3.00 \\
Addendum modification coefficient & 0 & 0 \\
Surface roughness, $R$ Ra $(\mu \mathrm{m})$ & 2.00 & 2.00 \\
Face width $(\mathrm{mm})$ & 30.00 & 15.00 \\
Pressure angle $\left({ }^{\circ}\right)$ & 20.00 & 20.00 \\
Helix angle $\left({ }^{\circ}\right)$ & 0.00 & 17.75 \\
Modulus of Elasticity $(\mathrm{GPa})$ & 228.00 & 228.00 \\
\hline
\end{tabular}

The lubricant employed during the entire test was Mobilgear 636 with Extreme Pressure (EP) in order to keep natural pitting and wear to a minimum. Properties of the lubricants employed during the test are detailed in table 2

\section{Table 2 Lubricant properties}

\section{Mobilgear 636}

\begin{tabular}{lc} 
Viscosity @ $40{ }^{\circ} \mathrm{C}(\mathrm{cSt})$ & 680.0 \\
Density @ $100^{\circ} \mathrm{C}(\mathrm{cSt})$ & 39.2 \\
Viscosity Index $\mathrm{C}(\mathrm{kg} / \mathrm{l})$ & 0.91 \\
Pour point $\left({ }^{\circ} \mathrm{C}\right)$ & 90.0 \\
Flash point $\left({ }^{\circ} \mathrm{C}\right)$ & -9.0 \\
Pressure viscosity coefficient, $\alpha\left(\mathrm{mm}^{2} / \mathrm{N}\right)$ & 285.0 \\
\hline
\end{tabular}

Different torque conditions were applied to the gear via a mechanism that allowed a pair of coupling flanges to be rotated relative to each other whereby the shafts were twisted and lock the torque within the loop of the back-to-back arrangement, see figure 1 . The 
torque applied on the gears was calibrated by measuring the strain on the shaft using Wheatstone half-bridge configuration located on the shaft connecting the two wheels.

Three different Alternating Current (AC) electrical motors rated at $0.55 \mathrm{~kW}, 1.1 \mathrm{~kW}$ and $2.2 \mathrm{~kW}$ were used to drive the test rig at three different speeds of 700,1450 and 2850rpm. A hand held digital tachometer was employed to measure the operating speeds of the gearbox.

\section{Figure 1 Back-to-back test gearbox arrangement}

The AE sensor used for the experiment was a wide band type sensor having a relative flat response between $100 \mathrm{kHz}$ and $1 \mathrm{MHz}$ at an operating temperature range of $-65^{\circ} \mathrm{C}$ to $177^{\circ} \mathrm{C}$ (WD model, 'Physical Acoustic Corporation'). The sensor was attached to the gear pinion by using strong adhesive, see figure 2 .

A 'J-type' thermocouple (Iron-Constantan) rated from $0^{\circ} \mathrm{C}$ to $200^{\circ} \mathrm{C}$ was employed to measure the lubricant and gear metal temperature during the test. Two thermocouples were mounted on the test pinion for recording the gear metal temperature and a third was located inside the oil bath. Figure 2 shows two of the three thermocouples mounted on the test pinion.

A silver contact slip ring was used to transmit the signal from the sensor and thermocouples on the rotating parts of the pinion to the data acquisition systems. The slip ring has the capacity to accommodate 12 channels with maximum speed of $20,000 \mathrm{rpm}$ at operating temperature range between $-20^{\circ} \mathrm{C}$ and $90^{\circ} \mathrm{C}$. The slip ring is 
capable of transmitting a maximum voltage of 50 volts and maximum current of 2 amps. The continuous silver connections ensure minimal thermal error making it compatible with thermocouple. The slip ring was located at the end of the test pinion shaft, see figure 1.

Figure 2 AE sensor and thermocouple location on test pinion gear

The output signals transmitted via the slip ring were then connected to commercial data acquisition card. The AE signals were pre-amplified at $20 \mathrm{~dB}$ and $40 \mathrm{~dB}$ during spur and helical gear test respectively prior to data acquisition card. Figure 3 shows schematic diagram of the DAQ system employed during the test.

\section{Figure 3 Schematic diagram of the Data Acquisition Systems}

Continuous AE r.m.s values were calculated in real time by analogue-to-digital converter (ADC) controlling software. The hardware accelerator employed by the software enabled the calculations of the AE r.m.s in real time to be performed. Each value from the ADC was squared and added into the accumulator by the hardware accelerator for a programmable time interval, 80 milliseconds in this instance which corresponds to approximately 0.93 revolution of the pinion at the lowest speed (700rpm). The r.m.s was calculated by taking the square root of the accumulated squared ADC readings. The accumulator is then cleared at the start of new time interval and the same process repeated. The time interval for the acquisition was set at 80 milliseconds. An anti aliasing filter was employed prior to the ADC card. AE waveforms were 
acquired at the sampling rate of $10 \mathrm{MHz}$ and $8 \mathrm{MHz}$ for spur and helical gears respectively. The waveforms were digitally filtered between $100 \mathrm{kHz}$ and $1200 \mathrm{kHz}$. Temperatures were recorded at the sampling rate of $1 \mathrm{~Hz}$ with the accuracy of $\pm 0.1 \%$ and a resolution of $1^{\circ} \mathrm{C}$.

\section{Experimental Procedure}

A series of tests was undertaken on both spur and helical gears in an attempt to understand the influence of load and speed on the generation of AE. Prior to every test, the gearbox was run until steady operating temperature was reached $\left( \pm 1^{\circ} \mathrm{C}\right.$ for the period of 30 minutes). AE r.m.s and gear temperatures were acquired in real time whilst $\mathrm{AE}$ waveforms were captured at different periods during each test.

The first set of tests was undertaken at constant speed of 700rpm with five different torque conditions of $60,120,180,250$ and $370 \mathrm{Nm}$. Tests were undertaken in increasing load conditions and were repeated three times. The rig was run for approximately 10 minutes under each load condition before the next load was applied.

The second set of tests was undertaken at three different speeds of 700, 1450 and 2850rpm. This test was undertaken at four load conditions of 60, 120, 250 and 370Nm. For this test, the rig was run for approximately 6 minutes on each speed condition.

\section{Experimental results and discussion}

\subsection{The influence of load on $\mathrm{AE}$}


Results from the first set of tests generally showed an increase in AE r.m.s as the load was increased for both spur and helical gears, see figure 4 and 5. The plotted values of AE r.m.s correspond to an average of 100 AE r.m.s data points acquired during the test. The results show repeatability in AE r.m.s values at each speed for all three tests on both spur and helical gears.

\section{Figure 4 AE r.m.s at different speed for spur gear}

\section{Figure $5 \quad$ AE r.m.s at different speeds for helical gear}

During these tests, the maximum variation in temperature at gear mesh ranged from $2.0^{\circ} \mathrm{C}$ for spur gears and $10.2^{\circ} \mathrm{C}$ for helical gears. Table 3 details the average temperature readings, oil viscosity, approximate oil film thickness, specific film thickness $(\lambda)$ and AE r.m.s values during the test. The values of AE r.m.s presented in table 3 were calculated based on 7000 AE r.m.s data points recorded for each test. The percentage decrease in specific film thickness $(\lambda)$ was calculated based on the reduction from the maximum value at $60 \mathrm{Nm}$ whilst the percentage increase in $\mathrm{AE} \mathrm{r.m.s} \mathrm{was} \mathrm{calculated} \mathrm{based} \mathrm{on} \mathrm{the}$ increase from the minimum r.m.s value at $60 \mathrm{Nm}$. It is interesting to note that the variation in largest temperature during these tests was for the helical gears.

The viscosity of the oil at the measured pinion temperature was calculated using the MacCoull equation, eq. (1) [13]. Oil film thickness was estimated during the test from eq (2) [7]. The oil film thickness estimated in this paper was based on the pinion temperature measured from the thermocouple close to the gear mesh, see figure 2. Hence, the approximation of the oil film thickness was believed to be much closer to the 
actual film thickness at the mesh as compared to the oil film thickness estimation by Tan and Mba [14] which was based on the oil bath temperature. Specific film thickness $(\lambda)$ is the ratio of oil film thickness over the composite surface roughness of the meshing surfaces, see eq. (3). Oil film thickness estimation is based on the assumption that pitch errors were very small and the load is acting along the line of action [15].

$$
\begin{gathered}
\ln \ln (v+0.7)=A+B \ln (T) \\
h=\frac{k\left(\eta_{0} \mu\right)^{0.7} R^{0.43}}{w^{0.13}} \mu m \\
\text { where, } \quad k=1.6 \alpha^{0.6} E^{0.03} \\
\lambda=h / \sigma_{r m s}
\end{gathered}
$$


Further analysis on the influence of load on the generation of AE activity is presented in figures 6 and 7. The variations in specific film thickness $(\lambda)$ under the same loading condition (Test 1,2 and 3) was due to different pinion temperatures during each test. The maximum temperature difference between the three different tests occurred at load condition of $120 \mathrm{Nm}\left(0.7^{\circ} \mathrm{C}\right)$ for the spur gear set and $60 \mathrm{Nm}\left(3.6^{\circ} \mathrm{C}\right)$ for the helical gear set. This gives the maximum specific film thickness $(\lambda)$ difference of 0.03 and 0.19 for spur and helical gear respectively. The AE r.m.s differences directly related to these temperature variations were 0.0008 Volts for spur gear and 0.0054 Volts for helical gear. These were relatively small compared to the average AE r.m.s for all three tests; 0.0112 Volts for spur gear and 0.1163 Volts for helical gear. These differences in temperature and associated specific film thickness $(\lambda)$ were considered relatively insignificant. Figure 6 and 7 illustrate that the increase in load resulted in an increase in AE levels, a direct consequence of the reduction in specific film thickness $(\lambda)$, and show a linear relationship. Theoretically, the reduction in specific film thickness $(\lambda)$ values implies that the levels of asperity contacts between the meshing surfaces will increase. The increase in AE r.m.s. levels with the reduction in specific film thickness $(\lambda)$ observed in this investigation strengthens the view presented by Tan et al [14] that the main source of $\mathrm{AE}$ during gear mesh is asperity interactions under sliding and rolling conditions.

Whilst AE levels were higher for helical gears during the mesh, the relative changes in AE levels as a function of changes in specific film thickness $(\lambda)$ were higher for spur gears, see Figure 8. It is interesting to note that Tan et al [14] had shown that the rolling action of spur gears contributed to the generation of the transient bursts at a periodicity equivalent to the gear mesh frequency whilst sliding during the mesh was attributed as the source of underlying continuous type $\mathrm{AE}$ waveforms. It is also known that the meshing mechanisms for a helical gear is progressive due to the gradual increase and 
decrease in contact length over a particular tooth whilst the spur gear mesh has a constant contact length throughout the gear mesh., i.e., unlike spur gear, the pitch point during helical gear mesh is not passed at the same time along the width of the gear. This results in the continuous occurrence of pure rolling at the pitch point in addition to the varying slide-to-roll ratio away from the pitch point at all times during helical gear mesh. This continuous pure rolling activity generates series of transient AE bursts which are very close to each other thereby forming a high amplitude continuous type waveform.

Lower amplitude AE signals resulted from complex combination of rolling and sliding were buried under this high amplitude continuous type of waveforms.

\section{Figure 6 AE r.m.s at different load and specific film thickness for spur gear}

\section{Figure $7 \quad$ AE r.m.s at different load and specific film thickness for helical gear}

The influence of load on the AE for both spur and helical gears can be summarized in figure 8 . The correlations obtained suggested that any percentage reduction in specific film thickness $(\lambda)$ will result in a corresponding increase in the percentage of AE r.m.s at levels of approximately 9.4 fold and 4.3 fold for spur and helical gear respectively, see gradient of slope in figure 8. The result suggests that the AE r.m.s during spur gear mesh is much sensitive to any changes in the specific film thickness $(\lambda)$ as compared to during helical gear mesh. This is attributed to the relatively higher influence of changes in the specific film thickness on the generation of $\mathrm{AE}$ from sliding in comparison to rolling. It is known that sliding is a source of $\mathrm{AE}$ as noted by Boness and McBride [4], Boness et 
al [5] and Price et al [6]. However, the helical gear mesh mechanism involves continuous rolling action at all times making it less sensitive to changes in specific film thickness.

\section{Figure 8 Relationship between percentage increase in $\mathrm{AE}$ r.m.s as the percentage of specific film thickness was reduced for spur and helical gears}

\subsection{The Influence of Speed on AE}

Figure 9 and 10 illustrate the changes in AE r.m.s for different pinion speeds on the spur and helical gear sets respectively. The plots show that the increase in speed results in the increase of AE r.m.s level for all load conditions. This result contradicts elastohydroynamic lubrication theory whereby the increase in speed should results in the increase of specific film thickness $(\lambda)$ under constant surface roughness and load condition thereby reducing the level of asperities between meshing surfaces [7]. If asperity contact is the only source of acoustic emission during gear mesh, the increase in speed should reduce the AE r.m.s as a direct consequence of the reduction in the level of asperities between meshing surfaces. However, this is not the case since the increase in AE r.m.s with the increase in speed is attributed to the higher strain rate experience by the asperities which generate larger amplitude $\mathrm{AE}$ response at higher speed and the contribution of friction of the lubricant between the gears in mesh [14]. The increase in speed will also increase the overall AE background noise levels from other gearbox 
components, i.e. bearings.. Interestingly Serrato et al [16] noted, for rolling element bearings, that the increase in speed should result in increased vibration damping experienced between the rolling element and the race way due to the increase in film thickness but this was not noted; Serrato attributed the increase in vibration levels with increasing speed to the change in dynamics of all contributor components of the system which resulted in increased vibration levels. It would have been of significant value had Serrato been able to assess the test bearing vibrations only.

Figure 9 AE r.m.s for spur gear speed variation test (a) $60 \mathrm{Nm}$ (b) $120 \mathrm{Nm}$ (c) $250 \mathrm{Nm}$ (d) $370 \mathrm{Nm}$

Figure 10 AE r.m.s for helical gear speed variation test (a) $60 \mathrm{Nm}(\mathrm{b}) 120 \mathrm{Nm}(\mathrm{c})$ $250 \mathrm{Nm}$, (d) $370 \mathrm{Nm}$

Table 4 and 5 detailed the measured values of temperatures and AE r.m.s and the calculated values of specific film thickness $(\lambda)$ at different load and speed conditions for both spur and helical gears. Oil viscosity, oil film thickness and specific film thickness ( $\lambda$ ) were estimated using eq. (1)-(3). The specific film thickness $(\lambda)$ and mean AE r.m.s from this table were used to further understand the influence of speed and load on the generation of AE activity and the source of AE during gear mesh, see figures 11 and 12 . The values of AE r.m.s presented in table 4 and 5 were averaged over 2000 AE r.m.s data points recorded during each test. Interestingly, the temperature variations during these tests were relatively constant. The maximum temperature variation during the tests was $3.2^{\circ} \mathrm{C}$ (at $250 \mathrm{Nm}$ ) and $9.6^{\circ} \mathrm{C}$ (at $370 \mathrm{Nm}$ ) for spur and helical gear respectively. Temperature variations during this investigation were generally higher in helical gear 
tests as compared to spur gear tests. This was due to the smaller face width on the helical test gears which will result in a higher load per unit length, thereby generating higher temperatures. 
The maximum temperature difference during the test under the same load and speed condition was $2.6^{\circ} \mathrm{C}$ (at $1450 \mathrm{rpm}, 250 \mathrm{Nm}$ ) and $7.5^{\circ} \mathrm{C}$ (at $1450 \mathrm{rpm}, 370 \mathrm{Nm}$ ) for spur and helical gears respectively (tables 4 and 5). This gives the specific film thickness $(\lambda)$ difference of 0.17 for spur gear test and 0.22 for helical gear test. The difference in $\mathrm{AE}$ r.m.s for this variation in temperature was 0.0092 Volts for spur gear and 0.0354 Volts for helical gear. These were relatively small compared to the average AE r.m.s where the maximum temperature differences occur during the test; 0.0740 Volts for spur gear and 1.1843 Volts for helical gear. The variation of AE activity due to the temperature difference under the same load and speed condition was assumed to be small.

Based on the experimental results presented, the influence of load on the generation of AE under combination of rolling and sliding (Spur gear, figure 11) would also appear to be a function of speed. At 700 and 1450rpm the variation of AE r.m.s with load was small as compared to the variation at $2850 \mathrm{rpm}$. It is important to note similar conclusion was reached by Tan and Mba [14]. The range of specific film thickness $(\lambda)$ under which Tan and Mba [14] undertook experiments was less than 0.5, as shown in grey region of figure 11. It should be noted that predictions of specific film thickness $(\lambda)$ by Tan and Mba [14] were based on the oil bath temperature which is considerably lower than the temperature at the gear mesh surfaces. As such, it is highly likely that the actual specific film thickness $(\lambda)$ values presented by Tan and Mba.[14] were lower than 0.5 . This implies that the gears tested by Tan and Mba [14] experienced boundary lubrication where there is no significant change in the level of asperities between meshing surfaces under increasing load conditions. This results in no significant change in AE activity as concluded by Tan and Mba [14] reinforcing the view that asperity contact was the main source of AE activity during gear mesh. However, in this investigation, experimental tests were undertaken mostly in mixed elastohydrodynamic lubrication regime where the 
level of asperities between meshing surfaces can change significantly with oil film thickness. This results in the change of AE levels as the level of asperities between meshing surfaces changes with load.

A 3-dimensional plot depicting the variations of load, speed and normalized AE r.m.s for both spur and helical gears is presented in figures 13 and 14 and a numerical relationship depicting this interdependency is given in equations 4 and 5 . The normalization of AE r.m.s was undertaken by considering the minimum and maximum AE r.m.s value as ' 0 ' and ' 1 ' respectively. The AE r.m.s values between minimum and maximum levels were calculated as a ratio between ' 0 ' and ' 1 '. The fit error $\left(\mathrm{S}_{\mathrm{e}}\right)$ and coefficient of determination $\left(\mathrm{R}^{2}\right)$ for eq. (4) were 0.070 and 0.951 respectively whilst for eq. (5) the corresponding values were 0.079 and 0.952 respectively. The loads employed in these equations are load per unit length applied on the gear face. The corresponding load per unit length applied on the gear was calculated based on the torque applied on the wheel shaft, see table 6. The difference in load per unit length between spur and helical gears under the same torque load was due to the difference in gear facewidth, refer table 1 . The minimum contact length for spur and helical gears were $30.00 \mathrm{~mm}$ and $20.33 \mathrm{~mm}$ respectively. This results in higher load per unit length experienced in helical gear under the same torque.

Table 6 Equivalent load per unit length calculated from the torque load

\begin{tabular}{|c|c|c|}
\hline \multirow[b]{2}{*}{ Torque $[\mathrm{Nm}]$} & \multicolumn{2}{|c|}{ Load $[\mathrm{kN} / \mathrm{m}]$} \\
\hline & Spur & Helical \\
\hline 60 & 20.51 & 26.77 \\
\hline 120 & 41.03 & 53.54 \\
\hline 250 & 85.47 & 111.54 \\
\hline 370 & 126.50 & 165.08 \\
\hline
\end{tabular}




$$
\ln (z)=3.795-82.284 / x^{1.5}-202.844 / y^{0.5}
$$

$$
\begin{aligned}
\ln (z)= & 2.767-2.591 / x^{0.5}-135.567 / y^{0.5} \\
& \text { where }
\end{aligned}
$$

$$
\begin{aligned}
& x=\text { Load in } \mathrm{kN} / \mathrm{m} \\
& y=\text { Speed in } \mathrm{rpm} \\
& z=\text { Normalized AE r.m.s }
\end{aligned}
$$

Equations 4 and 5 were developed based on several assumptions;

a. There is no significant change in gear surface roughness throughout the entire test

b. The variations in temperature during the test have minimal influence on the AE

c. There is no influence due to misalignment, unbalance and pitch errors

d. All loads are acting along the line of action and the length of contact line for helical gears was assumed to be at the minimum.

e. Temperature gradient between surfaces at the gear mesh and location where temperature data was acquired was small

f. The speed range employed was between 700rpm and 2850 and the load range employed was as stated in table 6.

Figure 11 AE r.m.s at different speed, load and specific film thickness for spur gear 


\section{Figure 12 AE r.m.s at different speed, load and specific film thickness for helical gear}

Figure 13 Estimation of speed, load and AE r.m.s relation for spur gear

\section{Figure 14 Estimation of speed, load and AE r.m.s relation for helical gear}

Analysis on the influences of speed and load on AE r.m.s was undertaken based on the equations developed earlier (equations (4) and (5)). From equation (4) and (5). Doubling the speed from 700rpm to 1450rpm increased the normalized AE r.m.s values by approximately 10- and 5-fold for spur and helical gears respectively. By increasing the speed from 700rpm to 2850rpm (an approximate 4-fold increase) results in the increase of normalized AE r.m.s values by approximately 48- and 13-fold for spur and helical gears respectively. Since the increase in AE levels with the increase in speed is attributed to the increase in strain rate experienced by the asperities [14], the results again suggest that sliding has a significant influence in changes in AE levels. It should be noted that the increases are relative and do not suggest that $\mathrm{AE}$ levels are higher for any particular gear type; only that the sensitivity to change is higher for the spur gear set.

In addition, by increasing the load to approximately 2- and 6-fold (from $20.51 \mathrm{kN} / \mathrm{m}$ to 41.03 and $126.50 \mathrm{kN} / \mathrm{m}$ ) results in the increase of normalized $\mathrm{AE}$ r.m.s values by approximately 1.8- and 2.3-fold, and, 1.2- and 1.4-fold for spur and helical gears respectively. Theoretically, under constant speed and isothermal conditions, increasing the load to approximately 2- and 6-fold on both spur and helical gears results in the reduction of specific film thickness $(\lambda)$ of approximately 10 and 20 percent of its original 
value. These estimates of changes in AE suggests that the influence of load on $\mathrm{AE}$ is higher under the influence of sliding (spur gear) as compared to continuous pure rolling (helical gear) and agrees with the earlier finding that $\mathrm{AE}$ is more sensitive to the changes in specific film thickness $(\lambda)$; a direct consequence of changes in load conditions only, under the combination of rolling and sliding (spur gear), see figure 8 .

Based on the estimation developed (equations 4 and 5), speed clearly has significant influence on the generation of AE as compared to load. This holds true for the speed and load range employed during the test. In general, the results agree with Bones et al $[4,5]$ whereby under asperity contact the increase in load and speed increased the AE level.

\subsection{Source of AE during spur and helical gear mesh}

Figure 15 and 16 shows AE waveform for spur and helical gear at 700 and 1450rpm at $250 \mathrm{Nm}$. The AE transients are clearly visible in spur gear waveforms as compared to helical gear waveforms. The maximum amplitude at each burst on the spur gear waveform is attributed to the $\mathrm{AE}$ activity generated from pure rolling at the pitch line [14] whilst the varying AE amplitudes away from the peak are attributed to the different slide to roll ratios away from pitch line, see figure 15.

Waveforms associated with the helical gear mesh are of the continuous type representing the $\mathrm{AE}$ activity due to continuous rolling activity at the pitch points.. Continuous rolling activity during helical gear mesh results in series of $\mathrm{AE}$ transient bursts that are closely spaced as to form high amplitude continuous type of waveforms. In addition, the continued variation in the contact length during meshing of helical gears [17], which 
directly influences the load conditions experienced by the gear, will lead to instantaneous changes in specific film thickness $(\lambda)$ thereby resulting in the amplitude variations of the continuous $\mathrm{AE}$ waveforms attributed to $\mathrm{AE}$ during the mesh. At the speed of 1450rpm the variation in AE amplitude is less visible compared to at 700rpm due to higher specific film thickness $(\lambda)$ value at this speed, thereby resulting in insignificant change in the asperity levels, see figure 16.

\section{Figure 15 AE waveform for spur gear test at load of $250 \mathrm{Nm}$}

\section{Figure 16 AE waveform for helical gear test at load of $250 \mathrm{Nm}$}

\section{Conclusion}

Several findings have been observed and established from this experimental research program.

1. AE is more sensitive to changes in specific film thickness under combination of rolling and sliding (spur gear) as compared to pure rolling (helical gear).

2. A numerical relationship between load, speed and AE for both spur and helical gears was established.

3. The variation in AE levels during helical gear mesh is speculated to be attributed to not only the influence of asperity levels but also to the variation in the contact length during meshing. 
The findings from this research program will form the foundations for significant advancement in applying AE to identify the lubrication regime within a gearbox thereby ensuring optimal conditions for prolonged life.

\section{Nomenclature}

$$
\begin{aligned}
& \alpha=\text { pressure exponent of viscosity }\left(\mathrm{Pa}^{-1}\right) \\
& E^{l}=\text { modulus of elasticity }(\mathrm{Pa}) \\
& \eta_{o}=\text { dynamic viscosity }(\mathrm{Pa}) \\
& u=\text { entraining velocity }(\mathrm{m} / \mathrm{s}) \\
& R=\text { equivalent radius }(\mathrm{m}) \\
& w=\text { load per unit length of cylinder }(\mathrm{N} / \mathrm{m}) \\
& v=\text { kinematic viscosity of the oil }\left(\mathrm{mm}^{2} / \mathrm{s}\right) \\
& T=\text { absolute temperature of the oil }(\mathrm{K}) \\
& A=\text { constant for specific oil } \\
& B=\text { constant for specific oil }
\end{aligned}
$$

\section{References}

1. Condition monitoring and diagnostic of machines. Acoustic emission general guidelines. ISO/DIS 22096, 2006.

2. Miller RK, McIntire P. Acoustic emission testing, $2^{\text {nd }}$ ed. Non-destructive testing handbook. American Society for Non-destructive Testing, vol. 5, 1987.

3. Mba D, Rao RBKN. Development of acoustic emission technology for condition monitoring and diagnosis of rotating machines; bearings, pumps, 
gearboxes, engines and rotating structures. The Shock and Vibration digest 2006;38(1):3-16.

4. Boness RJ, McBride SL. Adhesive and abrasive wear studies using acoustic emission techniques. Wear 1991;149:41-53.

5. Bones RJ, McBride SL, Sobczyk M. Wear studies using acoustic emission techniques. Tribology Int 1990;23(5):291-295.

6. Price ED, Lees AW, Friswell MI. Detection of severe sliding and pitting fatigue wear regimes through the use of broadband acoustic emission. J Eng Tribol, I Mech E, Part J 2005;219:85-98.

7. Dowson D, Higginson GR. Elastohydrodynamic lubrication, $1^{\text {st }}$ ed. Oxford, Pergamon Press, 1977.

8. Dowson D. Elastohydrodynamic and micro-elastohydrodynemic lubrication. Wear 1995;190:125-138.

9. Dowson D, Ehret P. Past, present and future studies in elastohydrodynamics. J Eng Tribol, I Mech E, Part J 1999;213:317-333.

10. Tan CK, Mba D. Identification of the acoustic emission source during a comparative study on diagnosis of a spur gearbox. Tribology Int 2005;38:469480.

11. Toutountzakis T, Mba D. Observation of acoustic emission activity during gear defect diagnosis. NDT\&E Int 2003;36:471-477.

12. Toutountzakis T, Tan CK, Mba D. Application of acoustic emission to seeded gear fault detection. NDT\&E Int 2005;38:27-36.

13. Alexander DL. The Viscosity of lubricant. Lubrication 1992;78(3).

14. Tan CK, Mba D. Experimentally established correlation between acoustic emission activity, load, speed, and asperity contact of spur gears under partial 
elastohydrodynamic lubrication. J Eng Tribol, I Mech E, Part J 2005;219: 401-409.

15. Larsson R. Transient Non-newtonian elastohydrodynamic lubrication analysis of an involute spur gear. Wear 1997;207:67-73.

16. Serrato R, Maru MM, Padovese LR. Effect of lubricant viscosity grade on the mechanical vibration of roller bearings, Tribology Int 2007;40:1270-1275.

17. Coy JJ, Townsend DP, Zaretsky EV. Dynamic capacity and surface fatigue life for spur and helical gears, ASME Journal of Lubrication Technology 1976;98(2):267-276. 